\title{
TUMOR MALIGNO DO SISTEMA NERVOSO CENTRAL ASSOCIADO A POLIPOSE DO CÓLON COM DEGENERAÇÃO MALIGNA
}

\author{
Luiz C. mattosinho França * \\ WiLSON Luiz SANvito **
}

Em 1959, Turcot e col. 7 relataram dois casos caracterizados pela associação de polipose familial com tumor maligno do sistema nervoso central, devendo ser assinalado que, nos dois casos, ocorreu transformação carcinomatosa de alguns polipos. Nessa época já era corrente a noção de polipose familial, isolada ou em associação com tumores de outra natureza e de diferentes localizações, como ocorre na síndrome de Gardner e suas variantes ${ }^{1,3}$.

Registramos, aqui, um caso no qual os polipos intestinais, alguns dêles com degeneração carcinomatosa, estavam associados a neoplasia encefálica da série gliomatosa.

\section{O B S E R V A C A O}

N.A.A., com 14 anos de idade, sexo feminino, branca, brasileira, internada na Clínica Neurológica em 31-5-1966 (R.G. 137.947). Em março de 1966 foi acometida de processo febril agudo, rotulado como gripe, durante o qual apresentou temperaturas superiores a $39^{\circ} \mathrm{C}$, recuperando-se em três dias. Nos dias que se seguiram, começou a referir tonturas, ao mesmo tempo que os familiares notaram que sua marcha já não era perfeitamente normal, pois ao deambular "entortava" o pescoço para um lado. Após 15 dias do episódio agudo, começou a apresentar crises de repuxamento na hemiface direita, de rápida duração, de aparecimento irregular, que chegavam a se repetir 5 a 6 vêzes num mesmo dia. Logo a seguir a paciente tornou-se excessivamente nervosa, além de apresentar certa dificuldade para deglutir. Com dois meses de evolução instalou-se estrabismo convergente no ôlho direito, além de franca dificuldade para a marcha, que passou a ser realizada sòmente com apôio. Antecedentes - Não há casamento consangüineo na famillia. Os pais e três irmãos estão vivos e gozam saúde. Exame clíniconeurológico - Estado geral regular; paciente afebril. Pressão arterial 110/70 $\mathrm{mm} \mathrm{Hg}$; pulso rítmico, com 96 batimentos por minuto. $\AA$ A ausculta dos pulmões, alguns roncos esparsos; abdome escavado, flácido e indolor, não apresentando tumorações palpáveis. Paciente lúcida, informando com precisão. Mantêm-se de pé alargando a base de sustentação; não há piora com os olhos fechados. Discreto déficit motor nos quatro membros, sendo mais evidente no membro inferior esquerdo. A manobra de Mingazzini observa-se queda lenta do memibro inferior esquerdo e, à manobra dos braços estendidos, discreto tremor na extremidade distal do membro superior esquerdo. As provas index-índex, index-nariz e cal-

Departamentos de Anatomia Patológica (Dr. L. C. Mattosinho França) e de Clínica Neurológica (Dr. Roberto Melaragno Filho) do Hospital do Servidor Público do Estado de São Paulo: * Patologista; * Neurologista. 
canhar-joelho evidenciam dismetria bilateral. Hipotonia generalizada. Fala escandida. Reflexo patelar diminuido à direita e sinal de Babinski à esquerda. No exame dos nervos cranianos observa-se: paresia dos músculos laterais, mais acentuada à direita; paresia do nervo facial direito e paresia velopalatina bilateral. Exames complementares - Foram realizados quatro exames do líquido cefalorraquidiano (um obtido por punção lombar e três mediante punção sub-occipital) durante a primeira internação, todos normais. Hemograma: hemoglobina 11,4 $\mathrm{g} \%$ ou $71 \%$; hematócrito $37 \%$; anisocitose, microcitose, poiquilocitose e hipocromia; 15.000 leucócitos por $\mathrm{mm}^{3}(1 \%$ de neutrófilos metamielócitos, $6 \%$ de neutrófilos bastonetes, $79 \%$ de neutrófilos segmentados, $1 \%$ de eosinófilos, $1 \%$ de basófilos, $8 \%$ de linfócitos, $4 \%$ de monócitos). Craniograma normal. Eletrencefalograma: sinais discretos de sofrimento cerebral na região occipital direita. Provas labirinticas (conclusão): inexcitabilidade vestibular bilateral. Campimetria: restrição concêntrica e global dos campos visuais bilateralmente. Exame dos fundos oculares: edema de papila bilateral. Evolução e tratamento - Já no primeiro dia de internação a paciente apresentou crise caracterizada por cefaléia, vômitos e repuxamentos na semiface direita; êstes sintomas se repetiram várias vêzes durante a internação. A partir do terceiro dia de hospitalização, começou a apresentar dispnéia e acúmulo de secreção salivar e brônquica, o que obrigou à traqueostomia e emprêgo de respiração assistida. Nesta ocasião, estavam sendo aáministrados corticóides por via intravenosa que foram suspensos pelo aparecimento de sangue nas fezes. Nos 10 dias seguintes a paciente se manteve com muita secreção salivar e brônquica. A partir do $13 .^{\circ}$ dia começou a apresentar melhora discreta e, no 24.0 dia, foi iniciada cinesiterapia. A afecção evoluía relativamente bem quando, em 12-7-1966 (42.0 dia de internação), o estado geral da paciente e o quadro neurológico se agravaram lentamente. Em 24-7 foi surpreendida enterorragia, sendo a paciente examinada por gastrenterologista, cujo relatório foi inconclusivo. Com o diagnóstico de glioma infiltrativo do tronco cerebral a paciente foi submetida à cobaltoterapia e apresentou nitida melhora, tendo obtido alta hospitalar em 23-9-1966, deambulando com apôio. Foi reinternada em 8-11-1966, porque apresentou quadro de diarréia com sangue nas fezes Ao exame neurológico observamos paciente prostrada, com fôrça muscular muito diminuida nos quatro membros, sendo o déficit mais evidente nos membros do hemicorpo esquerdo. Hipotonia generalizada; reflexos profundos exaltados no membro inferior esquerdo; sinal de Babinski à esquerda. Paresia bilateral do nervo facial; hipotrofia com fasciculações na hemilíngua direita. Exame dos fundos sculares: edema de papila bilateral. Desde o início da readmissão o caso evoluiu mal, com a paciente em péssimo estado geral, apresentando dor abdominal em cólica, além de sangue e muco nas fezes. Solicitado o concurso do gastrenterologista, foi constatada a presença de processo tumoral no reto, que se apresentava em grande parte prolapsado. O exame histopatológico de material colhido por biopsia revelou tratar-se de adenocarcinoma. A paciente continuou piorando progressivamente, com soluços intermitentes, febre, rigidez de nuca, hipertonia em flexão e secreção pulmonar abundante, vindo a falecer em 29-11-1966.

Necrópsia (A66-276) - Cadáver de adolescente em mau estado nutricional. No exame externo observa-se protrusão de massa nodular friável pelo orifício anal. O exame dos órgãos do pescoço, mediastino e tórax não mostra particularidades dignas de nota. Topografia da cavidade abdominal conservada. Mucosas do estômago e do intestino delgado sem alteraçōes. No cólon descendente foram encontrados dois polipos pediculados, medindo até $1,5 \mathrm{~cm}$ no maior diâmetro. A parede do sigmóide mostra, a $23 \mathrm{~cm}$ da linha pectínea, formação discóide, saliente na mucosa, com $5 \mathrm{~cm}$ de diâmetro e $1 \mathrm{~cm}$ de altura. A parede do sigmóide é invaginada a êsse nível, com extensa intuscepção intestinal, que se projeta externa. mente pelo orifício anal, correspondendo a massa descrita no exame externo do cadáver à tumoração da parede cecal. O exame histológico dessa tumoração mostrou tratar-se de adenocarcinoma, com infiltração da túnica muscular do sigmóide, não havendo comprometimento dos gânglios linfáticos regionais. As duas formações polipóides do cólon descendente são, histològicamente, polipos 

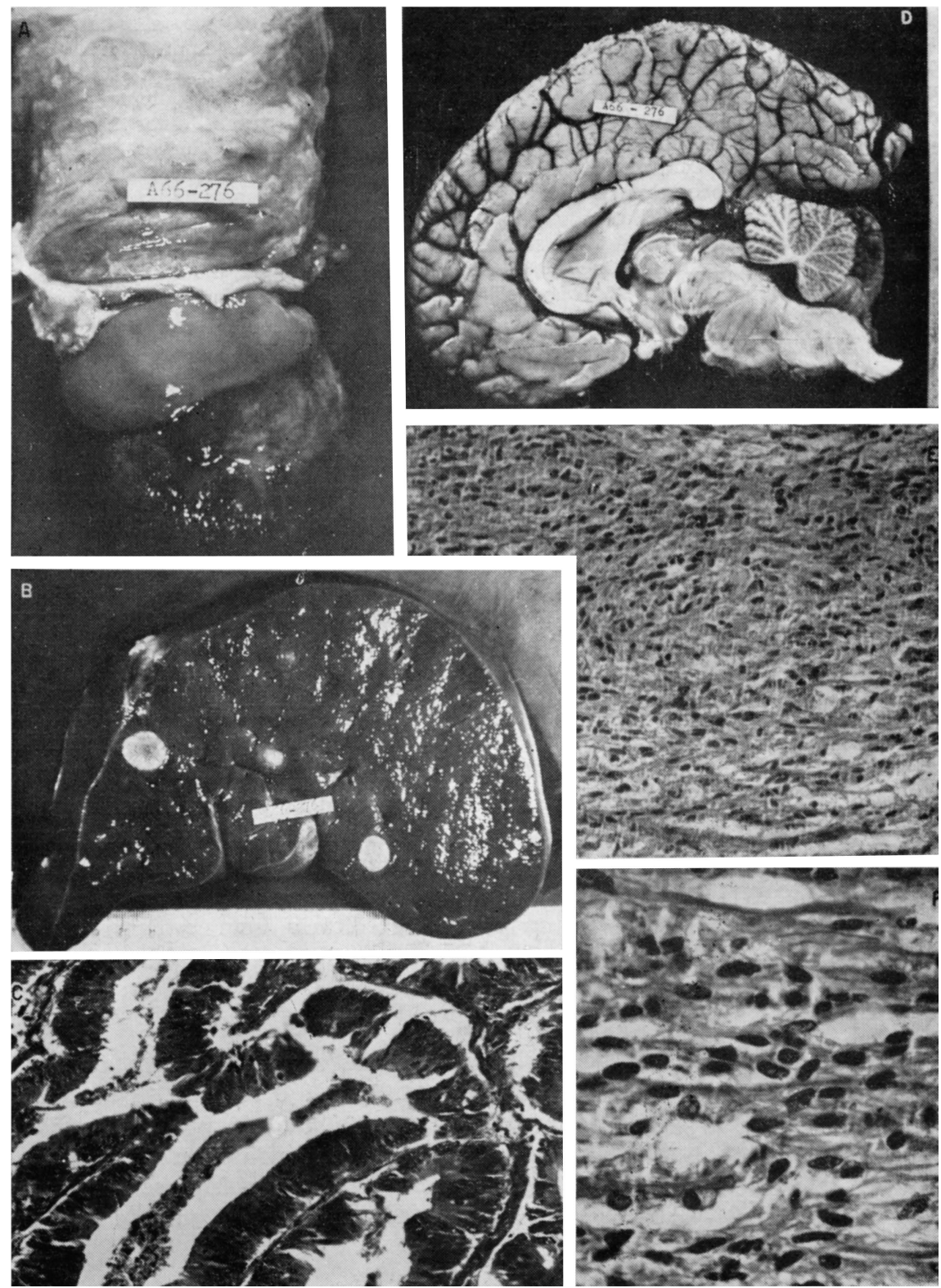

Fig. 1 - Caso N.A.A. Em A, adenocarcinoma do sigmóide com intuscepcão intestinal e prolapso através do orifício anal; em $B$, adenocarcinoma metastático no fígado; em $C$, microfotografia (H.E., 204 $\times$ ) de adenocarcinoma do sigmóide; em $D$, encéfalo com infiltracão neoplásica na porção basilar da ponte e no bulbo; em E, microfotografia (H.E., 204 $\times$ ) de espongioblastoma polar do tronco cerebral; em F, microfotografia (H.E., $512 \times$ ) de espongioblastoma polar do tionco cerebral. 
adenomatosos, com intensas atipías celulares. O fígado é aumentado de volume, contendo formações nodulares mủltiplas que, ao exame histológico, são características de metástases de adenocarcinoma. As demais vísceras abdominais não apresentam alteraçōes dignas de nota. $O$ encéfalo pesa $1.320 \mathrm{~g}$. A leptomeninge da face ventral do tronco cerebral é discretamente espessada. Os ventriculos laterais e terceiro ventrículo são moderadamente distendidos por líquido límpido. O tronco cerebral é discretamente aumentado de volume, havendo áreas granulosas, opacas, acinzentadas, confluentes, na porcão basilar da ponte, mesencéfalo e bulbo. Microscòpicamente observa-se, a êsses niveis, a presença de neoplasia maligna glial. Esta é formada por células alongadas, de tipo espongioblástico, cảspostas em feixes entrecruzados. Os núcleos são ovóides alongados, hipercromáticos. Focos de necrose estão presentes. Os diagnósticos anatômicos finais são de espongioblastoma polar do tronco cerebral, polipose colônica e adenocarcinoma do sigmóide com metástases hepáticas.

\section{COMENTARIOS}

A polipose intestinal pode ocorrer isoladamente ou em associação com tumores do sistema nervoso central, com tumores de outras naturezas e diversas localizações e/ou com pigmentação da pele e mucosas, caracterizando respectivamente as síndromes de Turcot, Gardner e Peutz-Jeghers. Na sindrome de Gardner, aos polipos adenomatosos do cólon, que podem evoluir para adenocarcinoma, se associam tumores ósseos (osteomas), comumente localizados na mandíbula, esfenóide e maxilar superior, e/ou tumores dos tecidos moles (cistos sebáceos, fibromas, fibrosarcomas, lipomas e leiomiomas). A síndrome de Peutz-Jeghers é caracterizada pela associação de uma pigmentação melânica, distribuída na região peri-oral e extremidades dos membros superiores e inferiores, com polipos de localização gastrintestinal. Os polipos localizam-se predominantemente no intestino delgado, porém, tem sido relatados casos de localização mais distal e até mesmo no reto. A transformação maligna dos polipos, nesta sindrome, ainda é matéria controvertida. Além da polipose familiar e das três síndromes mencionadas, que apresentam um fundo hereditário bem evidente, faz-se necessário mencionar a polipose colônica juvenil, que também apresenta uma base disgenética. Nesta, parece não haver transformação maligna dos polipos.

$\mathrm{Na}$ polipose intestinal pode ocorrer a transformação de um ou mais polipos em adenocarcinoma. De acôrdo com Lynch e Krush *, é calculado que cêrca de $40 \%$ dos pacientes com polipose familial já mostram evidência de câncer num primeiro exame (puberdade ou adolescência), percentagem que pode subir a $50 \%$ ao redor dos 30 anos. Também nas síndromes de Gardner e Turcot pode ocorrer a transformação maligna de um ou mais polipos.

A patogenia dessas diversas síndromes obedece a um mecanismo genético, nem sempre bem caracterizado. Enquanto que, na polipose familial e nas síndromes de Gardner e Peutz-Jeghers, o mođo de transmissão é autossômico dominante, na sindrome de Turcot ainda não foi estabelecida a modalidade de transmissão hereditária. É provável, do ponto de vista genético, que existam potencialidades blásticas num mesmo gene ${ }^{4}$. Dentro 
dêste conceito, cumpre assinalar a ocorrência, em algumas facomatoses, de tumores em vísceras ou em outros órgãos, como tem sido referido na esclerose tuberosa de Bourneville e na neurofibromatose de Recklinghausen ${ }^{5}$.

A análise de nosso caso revela aspectos que o identificam àqueles relatados por Turcot e col.1,2, ‘. Tanto nos dois casos relatados por Turcot e col. ' como em nosso caso, a moléstia teve início na puberdade, em todos ocorrendo transformação maligna da polipose intestinal e, em todos desenvolvendo-se tumores do sistema nervoso central da linha gliomatosa (meduloblastoma e glioblastoma multiforme nos casos de Turcot e col., espongioblastoma polar em nosso caso).

Os pacientes de Turcot e col. eram irmãos e seus pais primos em terceiro grau. A nossa paciente não era oriunda de casamento consangüíneo e seus irmãos, em número de três, não foram examinados por falta de colaboração da família.

\section{R E S U M O}

É relatado um caso caracterizado pela associação de tumor do sistema nervoso central e polipose do cólon. Foram encontrados apenas dois casos dessa natureza na literatura médica, relatados por Turcot e col. em dois irmãos, nos quais a afecção teve início na puberdade, caracterizando-se pela presença de tumor do sistema nervoso central associado a polipose do cólon; nos dois casos o tumor do sistema nervoso era da linha gliomatosa e ocorreu transformação carcinomatosa dos polipos. No caso aqui relatado, a moléstia teve início aos 14 anos de idade e, do ponto de vista histológico, foi encontrado um espongioblastoma polar no tronco cerebral associado a polipos múltiplos do cólon, alguns com degeneração carcinomatosa. Até o momento, a paciente estudada representa caso isolado em sua família.

\section{S U M M. A R Y}

Malignant tumor of the central nervous system associated with polyposis of the colon with malignant degeneration: a case report

A case of central nervous system tumor associated with polyposis of the colon is reported. A review of the literature shows two other such cases, reported by Turcot et al., and concerning two brothers. The symptoms of this association usually begin during puberty. All tumors described untill now are gliomas and colonic polyps have always suffered carcinomatous degeneration. The patient here concerned, a girl aged fourteen, had a spongioblastoma polare of brain stem with multiple polyposis of the colon and carcinoma in some of them. There are no other cases in the family. 


\section{REFER N N I A S}

1. BelleaU, R. \& BRAASCH, J. W. - Genetics and polyposis in systemic diseases and the gastrointestinal tract. Med. Clin. North America 2:379-392, 1966.

2. FRAUMENI, J. F.; VOGEL, C. L. \& EASTON, J. M. - Sarcomas and multiple polyposis in kindred: a genetic variety of hereditary polyposis? Arch. Intern. Med. 121:57-61, 1968.

3. GORLIN, R. J. \& ANAND, P. C. - Multiple osteomatosis, fibromas, lipomas and fibrosarcomas of the skin and mesentery, epidermid inclusion cysts of the skin leiomyomas and multiple intestinal polyposis. New England J. Med. 263: 1152-1165, 1960.

4. LYNCH, H. T. \& KRUSH, A. J. - Hereditary and adenocarcinoma of the colon. Gastroenterology 4:517-527, 1967.

5. RODRIGUES, H. \& BERTHRONG, M. - Multiple primary intracranial tumor in von Recklinghausen's neurofibromatosis. Arch. Neurol. 5:467-474, 1966.

6. SHIFFMAN, M. A. - Familial multiple polyposis associated with soft tissue and hard-tissue tumors. J.A.M.A. 179:514-522, 1962.

7. TURCOT, J.; DESPRÈS, J. P. \& St. PIERRE, F. - Malignant tumors of the central nervous system associated with familial polyposis of the colon: report of two cases. Dis. Colon Rectum 2:465-468, 1959.

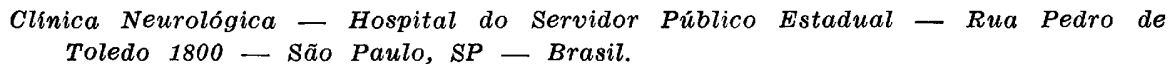

